\title{
Sex Discriminatory Effectiveness Using Combinations of Root Lengths and Crown Diameters
}

STANLEY M. GARN, PATRICIA E. COLE AND WALLACE L. VAN ALSTINE Center for Human Growth and Development, University of Michigan, Ann Arbor, Michigan 48109

\author{
KEY WORDS Teeth • Sex-discrimination - Odontometry . \\ Root length . Stepwise discriminant analysis
}

\begin{abstract}
Using optical-scanner (OPTOCOM) and radiogrammetric measurements on mandibular permanent teeth, root length alone affords sex-discriminatory effectiveness equal to or exceeding conventional crown diameters. Combinations of root lengths and crown dimensions yield up to $80 \%$ accuracy in sexing with as few as two teeth, and discriminatory effectiveness of $87 \%$ with mandibular teeth alone.
\end{abstract}

Root lengths of the permanent teeth are systematically characterized by a degree of sexual dimorphism greater than that for the corresponding crown dimensions of the same teeth (Garn et al., '78a). The root lengths of the permanent teeth moreover, prove to be largely independent of the conventional mesiodistal and buccolingual crown diameters (Garn et al., '78b). Under these circumstances, it might be expected that root lengths, alone, would show sex discriminatory effectiveness at least equal to the corresponding mesiodistal and buccolingual crown dimensions (cf. Garn et al., '77; Black, '78) and that combinations involving root lengths and crown diameters should further improve odontometric sex discrimination beyond levels previously attained (cf. Ditch and Rose, '72).

To test these various possibilities we have explored the value of radiogrammetrically. determined mandibular root lengths measured from the cemento-enamel junction to the apex of C-M2. This was done on $45^{\circ}$ oblique-jaw radiographs of 8316 - to 17 -yearold participants in the University of Michigan Longitudinal Study (Garn et al., '78a,b). Descriptions of the measuring technique, replicability and considerations of radiographic enlargement are given in our previous publications. In addition to the dial-reading caliper measurements of root lengths, made directly on the radiographs, we also employed mesiodistal and buccolingual crown diameters of C-M2. These were measured with an X-Y coordinate optical-scanner (OPTOCOM) as described by Van der Linden, Boersma, Zelders, Peters and Raaben in 1972 (Van der Linden et al., '72). Sex-discriminatory effectiveness using all 15 measures ( 3 for each tooth considered) was tested with a stepwise discriminant function program that allowed the incorporation of $\mathrm{N}$ variables, one at a time (Fox and Guire, '76). In this way, it was possible both to ascertain the discriminatory effectiveness of different combinations of crown size and root length and to determine those crown and root dimensions that contribute most to sex discrimination.

In the first of the analytic steps, we explored the proportion of individuals correctly sexed, using both individual measurements for each tooth (mesiodistal, buccolingual and root length) as well as combinations of crown measurements and root lengths. As shown in the first table (table 1), root length by itself attains discriminatory effectiveness generally equal to or greater than individual mesiodistal or buccolingual crown diameters alone. Despite unequal samples for the different teeth considered $-a$ function of the age and eruption status-single root lengths slightly exceed single crown diameters in the proportion correctly sexed for most of the measurements paired. Moreover, the combination of root and crown measurements (MD + BL + RL) generally achieve superior discriminatory effectiveness over single crown or root dimensions, tooth by tooth. 
With expectancy thus confirmed in the test sample, we then investigated the sex-discriminatory effectiveness of combinations of teeth and combinations of measurements from one through the maximum of 15 theoretically possible. Since only complete data sets could be used in the program, involving 15 measurements on five mandibular teeth for each subject, sample size was thus restricted to an $\mathrm{N}$ of 49 . Additional crown dimensional data on $I_{1}$ and $I_{2}$ were employed in a later analytical step as will be described.

Starting with the mandibular canine alone (the tooth with the greatest sex-discriminatory value in this subsample) single measurements yielded up to $73 \%$ correct identifications as shown for the buccolingual and mesiodistal crown dimensions in table 2. However, increasing the number of tooth measurements to six raised effective sex discrimination to $80 \%$ as also shown in the table. Beyond this level, increases in the number of teeth and the number of measurements raised discriminatory effectiveness only slightly. As shown in the table, and with each "new" dimension indicated at each step by underlining, some $84 \%$ discriminatory effectiveness was attained with a total of 13 odontometric measurements-comprising four root lengths, five mesiodistal crown diameters and four buccolingual dimensions. Beyond that level, there was no improvement in sex discriminatory effectiveness. It will be noted, however, that near-maximum sex discrimination can be achieved with a total of only six measurements on two mandibular teeth, i.e., C and M2.

In a third analytic step, we introduced crown-size data (but not root length data) on the mandibular incisors, thereby raising the tooth complement to seven of the eight teeth possible for any arch quadrant. With the addition of $I_{1}$ and $I_{2}$, there was a slight improvement in discriminatory effectiveness to a maximum of $87 \%$. For the record, this level

TABLE 1

Percent of single teeth correctly sexed ${ }^{1}$

\begin{tabular}{cccccc}
\hline Tooth & $\mathrm{N}$ & $\begin{array}{c}\text { Mesiodistal } \\
\text { (MD) }\end{array}$ & $\begin{array}{c}\text { Buccolingual } \\
\text { (BL) }\end{array}$ & $\begin{array}{c}\text { Root length } \\
\text { (RL) }\end{array}$ & MD + BL + RL \\
\hline $\mathrm{C}$ & 73 & 70 & 74 & 70 & 73 \\
$\mathrm{P}_{1}$ & 75 & 52 & 57 & 64 & 56 \\
$\mathrm{P}_{2}$ & 70 & 56 & 56 & 63 & 67 \\
$\mathrm{M}_{2}$ & 83 & 60 & 59 & 63 & 61 \\
$\mathrm{M}_{2}$ & 56 & 64 & 57 & 63 & 70 \\
\hline
\end{tabular}

${ }^{1}$ Tsing stepwise discriminant function program as given in Fox and Guire (76: pp. 155-156).

TABLF 2

\begin{tabular}{|c|c|c|c|}
\hline \multirow{2}{*}{$\begin{array}{l}\text { Mandibular } \\
\text { root lengths }\end{array}$} & \multicolumn{2}{|c|}{ Crown diameters } & \multirow{2}{*}{$\begin{array}{c}\text { Percent } \\
\text { correctly sexed }\end{array}$} \\
\hline & Mesiodistal & Buceolingual & \\
\hline $\mathrm{C}$ & - & - & 63 \\
\hline- & - & $\mathrm{C}$ & 73 \\
\hline- & - & $\underline{\mathrm{C}}$ & 73 \\
\hline- & $\underline{\mathbf{M}_{2}}$ & C & 76 \\
\hline $\mathrm{C}$ & $\overrightarrow{\mathrm{M}_{2}}$ & $\mathrm{C}$ & 76 \\
\hline $\overrightarrow{\mathrm{C}}$ & $\mathbf{M}_{2}$ & $\mathrm{C}, \underline{\mathrm{P}}_{1}$ & 76 \\
\hline $\mathbf{C}, \underline{\mathbf{M}}_{1}$ & $\mathrm{M}_{2}$ & $\mathrm{C}, \overline{\mathrm{P}}_{1}$ & 78 \\
\hline $\mathrm{C}, \overrightarrow{\mathrm{M}}_{1}$ & $\underline{\mathrm{C}} \mathrm{M}_{2}$ & $\mathrm{C}, \mathbf{P}_{1}$ & 80 \\
\hline $\mathrm{C}, \mathrm{M}_{1}$ & $\overline{\mathrm{C}}, \mathbf{M}_{2}$ & $\mathrm{C}, \mathrm{P}_{1}, \underline{\mathrm{P}}_{2}$ & 80 \\
\hline $\mathbf{C}, \mathbf{M}_{1}, \mathbf{M}_{2}$ & $\mathrm{C}, \mathrm{M}_{2}$ & $\mathrm{C}, \mathrm{P}_{1}, \overline{\mathbf{P}}_{2}$ & 80 \\
\hline $\mathbf{C}, \mathbf{M}_{1}, \mathbf{M}_{2}$ & $\mathrm{C}, \mathbf{M}_{1}, \mathbf{M}_{2}$ & $\mathrm{C}, \mathrm{P}_{1}, \mathbf{P}_{2}$ & 80 \\
\hline $\mathrm{C}, \mathrm{M}_{1}, \mathbf{M}_{2}$ & $\mathrm{C}, \mathrm{M}_{1}, \mathrm{M}_{2}$ & $\mathbf{C}, \mathbf{P}_{1}, \mathbf{P}_{2}, \underline{\mathbf{M}}_{1}$ & 78 \\
\hline $\mathbf{C}, \mathbf{M}_{1}, \mathbf{M}_{2}$ & $\mathrm{C}_{1} \underline{\mathrm{P}}_{1}, \mathbf{M}_{1}, \mathbf{M}_{2}$ & $\mathrm{C}, \mathbf{P}_{1}, \mathbf{P}_{2}, \mathbf{M}_{1}$ & 80 \\
\hline $\mathrm{C}, \underline{\mathrm{P}_{2}}, \mathrm{M}_{1}, \mathrm{M}_{2}$ & $\mathrm{C}, \mathrm{P}_{1}, \mathrm{M}_{1}, \mathrm{M}_{2}$ & $\mathrm{C}, \mathrm{P}_{1}, \mathrm{P}_{2}, \mathrm{M}_{1}$ & 82 \\
\hline $\mathrm{C}, \overline{\mathbf{P}}_{2}, \mathbf{M}_{1}, \mathbf{M}_{2}$ & $\mathrm{C}, \mathrm{P}_{1}, \underline{\mathrm{P}}_{2}, \mathbf{M}_{1}, \mathbf{M}_{2}$ & $\mathrm{C}, \mathrm{P}_{1}, \mathrm{P}_{2}, \mathrm{M}_{\mathbf{1}}$ & 84 \\
\hline $\mathbf{C}, \underline{\mathbf{P}}_{1}, \mathbf{P}_{2}, \mathbf{M}_{1}, \mathbf{M}_{2}$ & $\mathrm{C}-\mathrm{M}_{2}$ & $\mathrm{C}, \mathrm{P}_{1}, \mathbf{P}_{2}, \mathbf{M}_{1}$ & 84 \\
\hline $\mathrm{C} \cdot \overline{\mathbf{M}}_{2}$ & $\mathrm{C}-\mathrm{M}_{2}$ & $\mathrm{C}-\underline{\mathrm{M}}_{2}$ & 82 \\
\hline
\end{tabular}

Sample restricted to individuals with all 15 measurements. Measurements were introduced by the algorithm according to attained significance level. Underscoring indicates measurement newly included in that step. 
was attained with the following combination of teeth and dimensions:

$$
\begin{array}{ll}
\begin{array}{l}
\text { Root length: } \\
\text { Mesiodistal crown }
\end{array} & \mathrm{CP}_{1} \mathrm{P}_{2} \mathrm{M}_{1} \mathrm{M}_{2} \\
\begin{array}{c}
\text { diameter: } \\
\text { Buccolingual crown }
\end{array} & \mathrm{I}_{2} \mathrm{C}_{1} \mathbf{M}_{1} \mathbf{M}_{2} \\
\text { diameter: } & \mathrm{C} \mathrm{P}_{2} \mathbf{M}_{2} .
\end{array}
$$

Given the sample sizes employed in different parts of this study (49 for complete data and 83 for the incomplete data set), the levels of sex discrimination here attained with five to seven permanent teeth should not be taken as final estimates. Indeed, working with different-sized samples and up to 94 boys and girls and for root lengths alone, we have attained levels of sex-discriminatory effectiveness both above and below the values in the tables. The major point is the contribution of root lengths and discriminatory effectiveness attained by various combinations of root lengths and conventional crown diameters.

Nor are the present data on the relative importance of specific root lengths and particular crown diameters necessarily definitive because of the unique nature of the crown diameters (optical-scanner measurements made on an average of three casts per individual) and the inherent limitations of radiogrammetric root lengths on sub-adult individuals. The odontometric approach used would tend to increase discriminatory effectiveness as compared with measurements taken on single casts and with conventional calipers while the problems of radiographic positioning in vivo are necessarily greater than those that would obtain with skeletal material. Finally, it is important to emphasize that any discriminant function program is necessarily most effective for the particular sample from which it was derived.

It is heartening, nonetheless, to introduce the potential utility of root lengths in "sexing" human teeth, since root lengths have been but little employed in odontometric analyses either for the living or on skeletalized material as we have pointed out. It is further heartening to discover that close to $90 \%$ sex discriminatory effectiveness may be attained with mandibular teeth alone-ignor- ing the facial skeleton, the postcranial skeleton, and especially the pelvis. Clearly this approach may be of value to forensic anthropology where the teeth are often the best-preserved remains, and to skeletal collections. As one of the reviewers of this paper has pointed out, in fragmental collections and in cremated material, roots may be preserved and crowns not, thus adding to the potential utility of roots. Finally, and of additional interest to the living, there is the question asked of how these discriminant programs would "sex" the karyotypic abnormalities- $\mathrm{XO}, \mathrm{XO} / \mathrm{XX}, \mathrm{XO} /$ $\mathrm{XY}, \mathrm{XXX}, \mathrm{XXY}, \mathrm{XYY}$, etc. against established odontometric dimensions based on the normal $\mathrm{XX}$ and $\mathrm{XY}$, whether or not the sexes are equally well-discriminated in samples of truly adequate size.

\section{ACKNOWLEDGMENTS}

This work was supported in part by Grant DE 03610 from the National Institute of Health. We appreciate the programming assistance of Robert L. Wainright and that of Pat Bridges in the manuscript completion. The stepwise discriminant program embodies the contributions of Kenneth E. Guire, Statistical Research Laboratory, The University of Michigan.

\section{LITERATURE CITED}

B]ack, T. K. 1978 Sexual dimorphism in the tooth-crown diameters of deciduous teeth. Am. J. Phys. Anthrop., 48: 77-82.

Ditch, L. E., and J. C. Rose 1972 Multivariate dental sexing technique. Am. J. Phys. Anthrop., 37: 61-64.

Fox, D. J., and K. E. Guire 1976 Documentation for MIDAS. The University of Michigan Statistical Research Laboratory, pp. 155-156.

Garn, S. M., P. E. Cole, R. L. Wainright and K. E. Guire 1977 Sex discriminatory effectiveness using combinations of permanent teeth. J. Dent. Res., 56: 697.

Garn, S. M., W. L. Van Alstine, Jr. and P. E. Cole 1978a Root-length and crown-size correlations in the mandible. J. Dent. Res., 57: 114 (Abstract).

$1978 \mathrm{~b}$ Intra-individual root-length correlations J. Dent. Res., 57: 270.

- 1978c Relationship between root lengths and crown diameters of corresponding teeth. J. Dent. Res., 57 . 636.

Van der Linden, F. P. G. M., H. Boersma, T. Zelders, K. A Peters and J. H. Raaben 1972 Three-dimensional analy sis of dental casts by means of the OPTOCOM. J. Dent Res., 51: 1100 . 